\title{
Review Paper on Multi Notch Multi Polarization Antenna for Recent Wireless Communication
}

\author{
Oshee Surbhi Nandi \\ PG Scholar's \\ NIIST Bhopal
}

\author{
Teena Raikwar \\ Asst Prof \\ NIIST Bhopal
}

\author{
Swapnil Jain \\ HoD EC \\ NIIST Bhopal
}

\author{
Rahul Hatewar \\ Asst Prof \\ NIIST Bhopal
}

\begin{abstract}
In this paper reviewed and discuss multi notch multi polarization antenna for wireless communication, in past decade large number of research carried out, in the field of multi notch and multi polarization, the various application at specified frequency demanded notch antenna, multiple polarization and switch in polarization is strong needed, circular polarization antenna is versatile used in satellite communication, this paper review various technique to used in the designing of notch antenna, in some application needed antenna which exists linear as well as circular polarization, Over the period of time researchers have continuously contributed to improved the performance of antenna, that should be effective for modern communication. Research and development in this field have been reported by many researchers in the past few decades on the basis of different techniques. This type of antenna needed in, UWB, WLAN, satellite communication, GSM, and GPS. Dual-, triple- and quad-band antennas
\end{abstract}

\section{Keywords}

UWB, CMRC, DGS,

\section{INTRODUCTION}

Micro-strip antenna is more demanded in recent wireless technology due to low profile structure, compactness, flexible in installation, capable to operate in multiband, broad band and at multiple notches. Microstip antenna versatile used in GSM, Bluetooth Wi-Max,WLAN, Satellite communications, military communication, etc, in past decade multi-notch antenna is versatile used, many researcher's and scientists continuously work to design multi-notch antenna to gives multiple polarization in single antenna. In review section discuss about some technique to design this antenna

\section{REVIEW OF TECHNIQUES}

\subsection{Use Different type of patch shape}

From the study of multi notch and multiband micro-strip antenna, different type of patch shape gives the notches at specified frequency, fractal and planner inverted $\mathrm{F}$ type patches versatile used in present scenario, Diamond-shapedpatch (DSP) meander type patch [1], L-T-pi shape patches, UShape, square patch are capable to generates multiple notches with different polarization, The diamond-shaped-patch gives the broadband impedance bandwidth. To a multi-band antenna, narrow strips in DSP, acting as resonance circuit;

\subsection{Shorted parasitic inverted-L wire fed}

The shorting of parasitic patches is appropriate technique to generate multiple notches at different frequencies; this technique design in form of parasitic array, in paper [2] used this technique to generate three notches at $2.4 \mathrm{GHz}, 5.2 \mathrm{GHz}$, and 5.8-GHz WLAN bands. This type of antenna preferred as a monopole antenna as well as diversity antenna. The feeding system has designed in form of inverted L strip fed, the band $2.4 \mathrm{GHz}$ is WLAN band of frequencies range 2400-2484 $\mathrm{MHz}$, in the upper band of WLAN in the frequency range of $2843 \mathrm{MHz}$ of band 3930-to $6773 \mathrm{MHz}$, supporting HIPERLAN frequency band (5150-5350 MHz) and 5.8-GHz WLAN in the frequency range of $5725 \mathrm{MHz}$ to $5852 \mathrm{MHz}$ ). These band define for all three notches,

\subsection{Optimization of Ground Plane}

The optimization and appropriate design of ground plane is essential aspect to generate multiple notches [3], the theoretical dimension of length of ground plane is the summation of the length of patch and six times of height of antenna, the width of ground plane is the summation of the width of the patch and six times of height of antenna, inverted fork-shaped slit cutting in the ground plane is the recent method to generate multiple notches, different shape of ground is use in antenna design to provided optimization, like fractal shape, square, triangular, hexagonal, T-Pi shape. Slotting of the ground plane is the effective optimization technique, met material load in the ground plane also preferred.

\subsection{Different Shaped Resonator}

The loading of the resonator is another technique to generate multiple notches, resonator may be H-Shape, E-Shape, meander shape, ring type U-ring, complementary codirectional splitering resonator The notched frequencies can be design according to dimension and shape of the resonator. This technique gives high Q-factor at design notches; with improve return losses and impedance matching [4].

\subsection{Rectangle Slot With Trapezoidal Ground Plane}

The rectangle slot with trapezoidal ground plane is recently used technique in designing of notches antenna, to avoid interference problems in communication systems by nearby object within an ultra-wideband (UWB) operating frequency, a dual-band- compact notched UWB antenna is discuss [5]. This antenna design by rectangle slot with trapezoidal ground plane, a Y-shaped patch design as radiator, with adapted complementary splitering resonator design on the patch, which gives dual notched bands for lower frequencies and upper frequencies bands of the wireless local area network.

\subsection{Asymmetrical Slots on the Patches}

In this technique discuss, about the asymmetrical slotting technique on the patches [6], asymmetrical technique is also effective technique to gives multi notches with multiple polarizations, the stacked- patch arrangement is used for the antenna, and circular polarization is obtain by designing asymmetrical U-slots on the patches. The appropriate dimensions of the U-slots are optimized to gives circular polarization in two bands. The circularly polarized 
asymmetrical slotting technique used in Wi Max and at 5.8 GHz Hiper LAN.

\subsection{Passive Conducting Posts}

Loading of Passive conductive post is also attractive method to reduce reflection at specificied notch, in this technique contacted conductive post from patch to ground plane, this technique enhance the surface current at specified frequency, which can expect the resonant frequencies of all possible modes of a circular top patch radiator when encumbered with a number of passive conducting posts, circulated along the circumference of a patch radiator. where either the resonant frequencies can be tune in a expected method or a closely spaced dual-band antenna with flexible band taking apart is designed. It is also shown that for a disturbed circular patch TM01 is the mode with lowest non-zero resonant frequency [7].

\subsection{Photonic bandgap (PBG) structures,}

Photonic band-gap (PBG) structures is an another technique to gives multi notch, Photonic band-gap (PBG) structures consists of compact microstrip resonant cell (CMRC) and defected ground structure (DGS), Micro-strip antennas naturally have a high input impedance at specified resonance frequency. This may not be suitable for few applications. For active integrated antennas, furthermore, the power radiated of microstrip antennas desires to be very low at specified harmonic frequencies. This technique gives good impedance matching and suppression of harmonic of microstrip antennas. Photonic band gap structure design at feed line of microstrip antennas. The characteristic impedance of the microstrip line is appropriate design by the introducing effective inductance by photonic band gap structure. Without using matching network, photonic structure easily coupled with $50 \mathrm{ohm}$ microstrip antennas at specified frequency, and simultaneously successfully suppress the harmonic of the design antennas at specified notch frequency, compared to a theoretical antenna. PBG structure is compatible active integrated antennas to improve his performance [8].

\subsection{SLAMC (Stub-Loaded Artificial Magnetic Conductor) Structure}

In this technique using stub as a artificial magnetic conductor, is design in patch and ground plane, is design in many shape like E-H shape, This novel design is describe using the equivalent circuit, which represent that the loaded stub may be introduce an inter digital circuit in form of capacitance for perturbation of the surface current distribution, this structure gives impedance matching at specified frequencies, in addition, the improve of surface current and electric field density represent improve in radiation characteristics of antenna thus improves the aperture efficiency and gain, this technique describe in paper [9].

\subsection{Hybrid Resonant Configuration}

The hybrid resonant configuration is another aspect to improve the performance of multi-notches antennas, in this technique hybrid the dominant mode TM02 and circular-ring patch in form of monopole antenna, hybrid technique offering two notches bands, This coupling effect gives multi notches in proposed antennas, this mix modelling of resonant modes improve the performance of design antenna and gives good radiating charterstics[10]..

\subsection{Perturbation Segment Technique and Spur-Line Band-stop Filter [11]}

In the progressive steps notches antennas design perturbation segment technique and spur-line band-stop filter. This technique is also in form of hybrids of two design aspects first is segmentation techniques split geometry in form of segmentation as per as to design notches at multi frequency notches operation can be easily obtain without enhancing the dimension and area of the patch and ground plane.

\subsection{Optimization Using Algorithms}

Optimization using algorithm is versatile technique to obtain multiple notches at different frequencies [12], genetic, Powell, particle swarm optimization, iterative optimization algorithms and gradient-based algorithms for non linear problem program, random versatile used in notches design, the utilization of numerical codes in form of simulator is easily design as per as required operation. For finite boundary problem sequential quadratic programming optimization algorithm is versatile used.

\subsection{Band-Rejected Characteristics}

For generating notches at different frequencies band rejection characteristics is also preferred in antenna design, after notches impedance matching ratio is very poor using band rejection characteristics and impedance matching is very good at design notches, This type of antenna consist of bandrejected characteristics and microstrip line feed, with partial ground plane and ring patch, defective ground structure inform of rectangular shape is preferred. An annular strip is design above the radiating element using two slots, one arcshaped and other $\mathrm{C}$-shaped design in the radiating patch. The band rejection characteristics design using bio-inspired algorithms inform of the firefly algorithm and particle swarm optimization, the radiation characteristics is improve significantly and gives stable with high $\mathrm{Q}$ factor in the range of operating band improves the antenna efficiency and gain of the notches antenna at specified notches frequencies.

\section{CONCLUSION}

From Review of Multi Notch Multi Polarization Micro-strip Antenna concludes that Multi Notch Multi Polarization Micro-strip Antenna is demanded in modern applications such as portable devices like mobile handset, vehicles, navigation, Wi-MAX, IEEE 802.11 Wireless system, Satellite Communication System, Ultra, WLAN and GSM etc. Compactness and broadband techniques of antennas have been reviewed from past decades and discuss different technology. Some techniques shown in table 2, shows different technology used in past decades such as changing in shape and dimensions of patch and Ground plane, EBG Structure, Negative permeability and permittivity Meander's Ground plane technique, additional meta-material parasitic patches, via hole, high and low dielectric materials, meta material, different types of structures like inverted PLL U Type, Thick and thin substrate, Shorting pins and posts technique, Inverted shape patch L type, U -shape, H-Shape, Folded Shape, slotting technique, parasitic patches, inverted U-shaped or folded patch, stack type geometry , transmission line matching network has studied, Microstrip Antenna preferred modern wireless communication due to compactness and broadband features it also provides triple, dual band, multi band, multiples polarization from Single antenna and research is continuous going on. From survey of all techniques, it is concluded that more modification and improvements is required in micro-strip antenna. Further discussion and invention is required for portable and handheld 
devices like laptop, mobiles etc, in professional and industrial application, in table $-\mathrm{I}$ describe review of all techniques in terms of different antenna parameters shown below all techniques gives multi-notches with multiple polarization.

Table -I Review of different techniques

\begin{tabular}{|c|c|c|c|c|c|}
\hline Used technique & $\begin{array}{l}\text { Operating } \\
\text { impedance } \\
\text { bandwidth }\end{array}$ & $\begin{array}{l}\text { Antenna } \\
\text { efficiency }\end{array}$ & $\begin{array}{c}\text { Different } \\
\text { polarization }\end{array}$ & $\begin{array}{c}\text { Multiple } \\
\text { notches }\end{array}$ & Gain \\
\hline Use Different type of patch shape & Moderate & Moderate & Possible & possible & Moderate \\
\hline shorted parasitic inverted-L wire fed & Moderate & high & Possible & possible & high \\
\hline Optimization of Ground Plane & high & Moderate & Possible & possible & Moderate \\
\hline Different Shaped Resonator & Moderate & Moderate & moderate & possible & Moderate \\
\hline $\begin{array}{c}\text { Rectangle Slot With Trapezoidal Ground } \\
\text { Plane }\end{array}$ & high & Moderate & Possible & possible & high \\
\hline Asymmetrical Slots on the Patches & Moderate & high & Possible & possible & high \\
\hline Passive Conducting Posts & Moderate & high & Possible & possible & high \\
\hline photonic bandgap (PBG) structures & high & Moderate & Possible & Very effective & Moderate \\
\hline $\begin{array}{l}\text { SLAMC (Stub-Loaded Artificial Magnetic } \\
\text { Conductor) Structure }\end{array}$ & Moderate & Moderate & Possible & Very good & Moderate \\
\hline Hybrid Resonant Configuration & Moderate & high & Possible & Very good & high \\
\hline $\begin{array}{l}\text { Perturbation Segment Technique and Spur- } \\
\text { Line Band-stop Filter }\end{array}$ & Moderate & high & Possible & Very good & high \\
\hline Optimization Using Algorithms & As per required & $\begin{array}{l}\text { As per } \\
\text { required }\end{array}$ & $\begin{array}{c}\text { As per } \\
\text { required }\end{array}$ & As per required & $\begin{array}{c}\text { As per } \\
\text { required }\end{array}$ \\
\hline Band-Rejected Characteristics & Moderate & High & Possible & Very good & high \\
\hline
\end{tabular}

\section{REFERENCES}

[1] Foudazi, A. ; Electr. \& Electron. Eng. Dept., Shahed Univ,et.al "Small UWB Planar Monopole Antenna With Added GPS/GSM/WLAN Bands" Antennas and Propagation, IEEE. Volume:60 Issue:6 Page(s):2987 299203 May 2012

[2] Jen-Yea Jan ; Dept. of Electron. Eng., Nat. Kaohsiung Univ. of Appl. Sci., Taiwan ; Liang-Chih Tseng" Small planar monopole antenna with a shorted parasitic inverted-L wire for wireless communications in the 2.4-, 5.2-, and 5.8-GHz bands" Antennas and Propagation, IEE Volume:52 Issue:7 Page(s):1903 - 1905 , July 2004

[3] Ojaroudi, M. ; Young Res. Club, Islamic Azad Univ., Ardabil, Iran ; Ojaroudi, N. ; Ghadimi, N." Dual BandNotched Small Monopole Antenna With Novel Coupled Inverted U-Ring Strip and Novel Fork-Shaped Slit for UWB Applications" Antennas and Wireless Propagation Letters, IEEE (Volume:12 ) Page(s):182 - 185 February 2013

[4] Sung, Y.; Dept. of Electron. Eng., Kyonggi Univ., Suwon, South Korea" Triple Band-Notched UWB Planar Monopole Antenna Using a Modified H-Shaped
Resonator" Antennas and Propagation, IEEE Transactions on (Volume:61 , Issue: 2 )Page(s):953 957 October 2012

[5] Li, L. ; Inst. of Appl. Phys., Univ. of Electron. Sci. \& Technol. of China, et.al" Compact dual-band-notched UWB planar monopole antenna with modified SRR" Electronics Letters (Volume:47, Issue: 17 ) Page(s):950 - 951 August 182011

[6] Nayeri, P. ; Electr. Eng. Dept., Univ. of Mississippi, et.al, "Dual-Band Circularly Polarized Antennas Using Stacked Patches With Asymmetric U-Slots" Antennas and Wireless Propagation Letters, IEEE (Volume:10 Page(s):492 - 49512 May 2011

[7] Chakravarty, T.; Millimetre Wave Tech. Group, SAMEER, Calcutta, India ; De, A. "Design of tunable modes and dual-band circular patch antenna using shorting posts" Microwaves, Antennas and Propagation, IEE Proceedings (Volume:146, Issue: 3 ) Page(s):224 228Jun 1999

[8] Sung, Y.J. ; Dept. of Radio Sci. \& Eng., Korea Univ, et.al "An improved design of microstrip patch antennas 
using photonic bandgap structure" Antennas and Propagation, IEEE Transactions on (Volume:53, Issue: 5 )Page(s):1799 - 1804 May 2005

[9] Wanchen Yang; Dept. of Commun. Eng., et.al"HighGain Design of a Patch Antenna Using Stub-Loaded Artificial Magnetic Conductor" Antennas and Wireless Propagation Letters, IEEE (Volume:12 ) Page(s):1172 1175, September 2013

[10] Niroo-Jazi, M. ; INRS, Univ. de Quebec, Montreal, QC, Canada ; Denidni, T.A." A New Triple-Band Circular Ring Patch Antenna With Monopole-Like Radiation Pattern Using a Hybrid Technique" Antennas and Propagation, IEEE Transactions on (Volume:59, Issue: 10 ) Page(s):3512 - 351704 August 2011

[11] Sanchez-Hernandez, D. ; Dept. of Electron. \& Electr. Eng., London Univ., UK ; Robertson, I.” Triple band microstrip patch antenna using a spur-line filter and a perturbation segment technique" Electronics Letters (Volume:29, Issue: 17 )Page(s):1565 - 1566,19 Aug. 1993

[12] Zhifang Li ; Dept. of Electr. Eng. \& Comput. Sci., et.al," Designing broad-band patch antennas using the sequential quadratic programming method" Antennas and Propagation, IEEE Transactions on (Volume:45 , Issue: 11 ) Page(s):1689 - 1692 Nov 1997

[13] Mohammed, H.J. ; University of Basrah, Iraq et.al" Design of a uniplanar printed triple band-rejected ultrawideband antenna using particle swarm optimisation and the firefly algorithm" Microwaves, Antennas \& Propagation, IET (Volume:10, Issue: 1 ),Page(s):31 37,192016 